\title{
VIAJAR SIN MAPA
}

\section{Travel Without a MaP}

\author{
José Luis Escalona-Victoria*
}

DOI: http://dx.doi.org/10.29043/liminar.vl8il.734

F ue Martín López Ávalos, investigador del Centro de Estudios Históricos de El Colegio de Michoacán, quien originalmente invitó a varios colegas a discutir el tema de la historia del tiempo presente en un seminario que se reunió varias veces entre 2013 y 2017. Aunque convocados desde la historia, la mayoría de los participantes éramos antropólogos y, por ello, la preocupación condujo a rutas no previstas, lo que también refleja las trayectorias que ya recorría la discusión más allá del seminario. La invitación de López se tradujo en un texto que es el que abre el presente número de LiminaR. Estudios Socialesy Humanísticos. En su artículo, "Práctica historiográfica y ciencias sociales en México. Una aproximación a la historia contemporánea y del presente", López acerca al lector a las formas particulares y diversas que adquirió ese interés por lo contemporáneo, por la experiencia de lo que no está muerto y alojado en los archivos, sino vivo y en curso, en algunas instituciones de investigación histórica en México. A esta preocupación por el presente, argumenta el autor, le acompañó un replanteamiento de la propia disciplina histórica, sus fuentes, sus formas de aproximarse a su objeto y una especialización en subdisciplinas; además, implicó un encuentro con otras ciencias en su propio terreno - por ejemplo, la sociología, la politología o la antropología, que en cierta forma estaban más familiarizadas con el presente- - El proceso se expresa, entre otros efectos, en una creciente aparición de encuentros académicos, instituciones y publicaciones, y en una clara hibridación entre historia y otras ciencias sociales.

En una vía opuesta, el artículo "La etnografía, el presente y la idea de historia”, de José Luis Escalona Victoria, muestra un momento, finales del siglo XX, en el que algunos antropólogos buscaron "ser históricos". Ello significó, por un lado, explorar el pasado y su presencia en lo contemporáneo y, por otro lado, poner atención en las conexiones entre los procesos locales, familiares para los que hacen etnografía, y las redes de intercambios y relaciones más amplias. Esa búsqueda, planteada más claramente por Eric Wolf en su libro Europay la gente sin historia, marcó una forma de hacer etnografía en México. No obstante, como en el caso de la historia del tiempo presente analizado por López, hubo otras maneras de hacer historia en la antropología en México anteriores incluso al llamado de Wolf, como la etnohistoria o

* José Luis Escalona Victoria. Doctor en Antropología Social por la Universidad de Manchester, Reino Unido. Profesor-investigador en el Centro de Investigaciones y Estudios Superiores en Antropología Social (CIESAS), Unidad Sureste, México. Temas de especialización: antropología del poder, antropología de la antropología, etnografía del poder. Correo electrónico: joseluisescalona@prodigy.net.mx. ORCID: https:/orcid. org/0000-0003-1783-0142. 
la antropohistoria, entre otros ejemplos de híbridos surgidos a partir de las disciplinas establecidas entre fines del siglo XIX y el siglo XX.

A manera de comentario general, elaborado desde la antropología, Martin Larsson propone ir más allá de los márgenes de la discusión tal como se presenta entre los historiadores. En su artículo "Hacia una nueva historiografía. De la historia del presente a la filosofía con gente adentro", Larsson señala que la preocupación del historiador por el presente parece responder más a una definición política que a un giro en los fundamentos teóricos de la disciplina. Al partir de una idea del presente como época y de la sociedad como objeto, como sucede en la discusión sobre el Antropoceno, la historia no logra rebasar la impronta del cientificismo evolucionista. Una teleología parece rodear los intentos por definir no solo la dirección histórica, sino el aspecto determinante de la sociedad en una época específica. La definición del carácter de lo contemporáneo en la historia del presente reproduce esa preponderancia de una teoría de la sociedad contemporánea - una teoría mapeadora, como la llama Larsson- El problema tampoco parece resolverse por la vía de Foucault, esa anticiencia que explora las genealogías de los márgenes, las fisuras y las otras consecuencias de la sociedad en una época, dado que mantiene su foco en una teoría mapeadora previamente establecida, tan solo mirándola desde ángulos silenciados, dominados, excluidos. Frente a ello, Larsson propone dos caminos para dejar atrás conceptos como época y sociedad: una vía pragmática y una vía hermenéutica. La primera descansa en la propuesta de Latour que consiste en seguir a los objetos y personas como nudos de redes de relaciones, produciendo alianzas temporales en las que los objetos son más que simples mediadores. La segunda vía — que descansa en la distinción entre ratio e intellectus, de Jonna Bornemark - implica conversar con personas que viven en los documentos de archivo, simplemente para enfrentar ideas tan extrañas que hagan nuestro presente algo exótico. Mientras que la idea de mapear el mundo con una teoría preconstruida es la lógica del tipo ratio, la conversación que exotiza, y por ello abre la mirada a nuevos objetos, esos que no se dejan mapear, lleva a la lógica del intellectus. ¿No hay un cierto paralelismo entre este cuestionamiento de Larsson a los conceptos de sociedad y época, con el que hace Wolf respecto de la sociedad y la cultura, justo por funcionar como teorías mapeadoras? Tampoco parece extraño que la consecuencia fuera un enfoque en redes y conexiones. Quizás la diferencia fundamental radica justo en que en el caso de Wolf no deja de haber una teoría mapeadora, aquella que está enfocada en el modo de producción y la relocalización de la fuerza de trabajo, mientras que Larsson explora sin mapa, siguiendo alianzas de cosas y personas, generando conversaciones extrañas que terminan por hacer del mapa mismo un objeto exótico.

Se puede, por ejemplo, viajar persiguiendo los textiles. Tomando un camino distinto al de Latour —que Larsson llamó la vía pragmática一, en su texto "Mercancías únicas. La fantasía ideológica de la producción de textiles artesanales" Julieta Flores Montes examina cómo se dota a los textiles de cualidades estéticas y culturales, por la forma en que son producidos y por el carácter de los productores, para darles una imagen de prendas únicas. Julieta Flores explora cómo en las tiendas de la ciudad de San Cristóbal de Las Casas, Chiapas, en especial aquellas de moda y diseños étnicos, se exalta no la utilidad de la pieza, sino su producción manual, la habilidad del artesano, la antigüedad del diseño y la técnica. Pero es justo el trabajo y la colaboración entre los propios artesanos, los comerciantes y los consumidores lo que crea esa fantasía, ya sea por la ruta de una biografía del producto o por la ruta del mercado justo y el consumo responsable. El viaje que hace Flores, acompañada de Žižek, por los mecanismos de interpelación en torno a la fantasía - que reproduce la desigualdad, pero también las esperanzas de un pago justo - muestra de manera directa un nudo en la forma contemporánea en que surge la ilusión fetichista de la mercancía.

En la misma ciudad de San Cristóbal, por los espacios públicos, se puede explorar igualmente la producción de imágenes. En "Relatos a la espera. Muralismo urbano en los espacios públicos de San Cristóbal de Las Casas, Chiapas", María de Lourdes Morales Vargas muestra una pintura mural que más 
parece hacer eco del famoso muralismo mexicano de la primera mitad del siglo XX, sobre todo por su dirección hacia la búsqueda de identidad, con narrativas visuales que reutilizan motivos recurrentes de esa escuela pictórica mexicana. Otro aspecto significativo, que igualmente conecta el muralismo actual con su ancestro, es su carácter público y, por ello, pedagógico, que busca configurar el presente de las audiencias al momento mismo de cruzar el espacio público. No obstante, tanto en estilo como en concepto, Morales argumenta que los nuevos murales parecen estar explorando formas más inclusivas y plurales de la identidad. Una señal de esa transformación es la mezcla de los antiguos motivos con otros, provenientes de los comics, la protesta social y figuras surrealistas.

En el artículo "El núcleo ético-mítico de la filosofía en Abya Yala", Gabriel Herrera Salazar explora la posibilidad de la existencia de la filosofía en la sociedad del continente previa a la llegada europea en el siglo XVI, lo que se demuestra, entre otros factores, a través de los mitos fundacionales, que comparten elementos sustanciales comunes en los diversos pueblos del continente. El autor hace un recorrido por elementos que sostienen esta premisa, como los conceptos de dualidad y complementariedad, así como los diferentes conceptos de cuerpo y mente, que podrían revelar un fundamento filosófico en los pueblos indígenas de Abya Yala.

En el texto "El liderazgo 'mandar obedeciendo' se fundamenta en el sacrificio del hermano mayor", Ana Bertha García Bravo y Manuel Roberto Parra Vázquez analizan una modalidad de liderazgo basado en la figura del bankilal, hermano mayor, en los pueblos tsotsiles de Chiapas, como una forma de autoridad que es consistente con la noción zapatista del mandar obedeciendo. Tras un recorrido por distintos tipos de liderazgos que también se encuentran presentes en estos pueblos, como los liderazgos comunitarios, los autores reflexionan sobre el liderazgo que llaman "mandar obedeciendo", según el cual la comunidad es la que ejerce poder sobre el líder que ha elegido con base tanto en rasgos motivacionales, como en capacidades. Pero la cualidad principal que busca la comunidad es el sacrificio, que va en consonancia con el bankilal, el hermano mayor, quien tiene el mandato de cuidar a los hermanos menores y de dejar a un lado sus intereses por el bienestar de la comunidad.

El tema de la interculturalidad vuelve a ser analizado, cuestionado y reelaborado en un conjunto de textos incluidos en el presente volumen. En su artículo "La interculturalidad y la salud: reflexiones desde la experiencia”, Enrique Eroza Solana y Mónica Carrasco Gómez revisan la forma en que los marcos de la interculturalidad en los servicios de salud en México han fijado su atención en un solo aspecto: la colaboración entre la llamada medicina alópata y la medicina indígena. La propuesta de Eroza y Carrasco, en cambio, implica abrir la mirada a dos aspectos fundamentales para la atención médica. Uno es el estudio detallado de las diversas interacciones que se dan en los servicios de salud, más allá de la dualidad alópata/indígena, considerando muchos otros ángulos de interculturalidad posibles. El otro es considerar las interacciones no solo en el contexto de la atención médica, sino en el conjunto de la vida de las personas.

Además de las dos líneas señaladas por Eroza y Carrasco, el siguiente artículo de este número apunta a otra línea de reflexión en el tema de la interculturalidad. "Antsiwinik. Expresarse como homosexual en una secundaria de contexto indígena”, de Amadeo Hernández, Rogelio Ernesto Marcial y Manuel Alejandro Moreno, muestra un ángulo de la interculturalidad con nula presencia en los espacios educativos. Se trata de un estudio sobre estudiantes con identidades sexo-genéricas diversas en una localidad de Ocosingo, que enfrentan en la escuela y la comunidad formas de rechazo y violencia. Los autores observan, además de las experiencias cotidianas de los estudiantes, otras que tienen que ver con la institución misma. Mientras que los programas oficiales proponen estrategias específicas con perspectiva intercultural para grupos con culturas diferentes, no ponen atención a ese otro ángulo de la interculturalidad que implica la convivencia entre personas con diversas identidades de género.

En "Infancia escolarizada en zonas rurales de la costa de Chiapas: condiciones de centros educativos preescolares", Martín Plascencia González y Kathia 
Núñez Patiño presentan también resultados de una investigación en escuelas preescolares de la zona Costa de Chiapas. Además de identificar muchas carencias en las condiciones para el proceso de enseñanza aprendizaje, hacen señalamientos particulares en dos aspectos adicionales: la atención de la discapacidad $y$, sobre todo, la carencia de una visión general de interculturalidad en un sentido amplio, es decir, en la convivencia de la escuela con conocimientos, saberes y prácticas locales.

En el texto "Logros y retos de una universidad autónoma en su rol de formar ciudadanía: la perspectiva de sus estudiantes", Jorge Isaac Manuel Ortega analiza el impacto que tiene la presencia de un centro universitario de la Universidad de Yucatán en la formación de ciudadanía. Por un lado, señala, la vida universitaria ofrece una serie de recursos y experiencias que amplían los vínculos y las expectativas de los estudiantes, lo que contribuye a modificar el desarrollo de ciudadanía. Esas experiencias son analizadas en cuatro rubros: promoción del uso de la razón y del diálogo fundamentado, oportunidades para el desarrollo individual y la movilidad social, conciencia social y ética de la convivencia, y análisis y debate de problemas sociales. Sin embargo, la misma estructura universitaria pone límites a esa expansión de ciudadanía. Un interesante estudio para hacer trabajo comparativo con otros centros universitarios en distintos lugares del país.

"La exclusión social y las Tecnologías de la Información y la Comunicación: una visión estadística de su relación en la educación superior", de Martha Patricia Astudillo, Florlenis Chévez y Yesenia Oviedo, ofrece un análisis de los efectos de la presencia de las Tecnologías de la Información y la Comunicación (TIC) en la educación universitaria a partir de dos investigaciones concretas en México y Costa Rica. Los resultados del estudio nos plantean una paradoja: aunque sin duda esta tecnología abre nuevas oportunidades y experiencias en las prácticas educativas universitarias, su manejo y aprovechamiento es desigual, lo que crea una brecha importante entre estudiantes a partir del manejo diferenciado que pueden hacer de esa tecnología.
En el último artículo que se ofrece en este número de LiminaR. Estudios Sociales y Humanísticos, que lleva por título "Efectos de la reforma energética en el territorio y condiciones socioeconómicas en Papantla, Veracruz, México", Elvira Nuñez, Yolanda Sánchez y Aníbal Terrones, a partir de un estudio en comunidades de Papantla, Veracruz, analizan las consecuencias de la reforma energética de 2013 y 2014. Lejos de llevar bienestar, la reforma ha resultado en el mantenimiento de los niveles de pobreza previos, además de la continuidad en los daños ambientales que genera la industria del ramo.

Markéta Kř̌́žová, investigadora de la Universidad Carolina en Praga, reconocida con la Cátedra Jan de Vos 2018 (CIESAS-ECOSUR), colabora en este número con el documento de un viajero checo que estuvo en la segunda década del siglo XX en México. En su introducción, que lleva por título "Alois Richard Nykl: un arabista checo en Yucatán”, Křížová reseña tanto los avatares del autor, como de su archivo. Una conversación con Nykl, en el sentido que sugiere Larsson, podría sugerir formas alternativas de mirar Yucatán en los años posteriores al asesinato de Felipe Carrillo Puerto, un momento pleno de disputas por la figuración del México posrevolucionario.

El número cierra con dos reseñas. En la primera de ellas Diana Guillén reflexiona sobre el libro Antología del ensayo moderno en Chiapas: esbozo de una historia cultural, un recorrido "sugerente y provocador" que propone Ignacio Ruiz Pérez sobre el entramado cultural chiapaneco. En la segunda, que lleva por título "Socialismo y vanguardia vernácula yucateca (1918-1956)”, Sonia Irene Ocaña-Ruiz ofrece una sugerente revisión del libro El arte monumental del socialismo yucateco (1918-1956), de Marco Aurelio Díaz Güemez, obra que describe el proceso de producción de arte monumental del régimen posrevolucionario socialista en Yucatán durante la primera mitad del siglo XX.

Este número de la revista LiminaR. Estudios Sociales y Humanísticos está acompañado de cinco fotografías de la colección Viviendo el pasado, del año 2017, de la artista, fotógrafa y escultora del Estado de México Irma Karen Pichardo Beltrán. 